\title{
Optimasi Stok Ayam Potong Menggunakan Metode Fuzzy Tsukamoto Di Rumah Makan Boyolali
}

\author{
Helfa Renita Berlian ${ }^{1)}$; Muhammad Hasbi ${ }^{2}$; Kustanto ${ }^{3)}$ \\ 1) 2) 3) Teknik Informatika, STMIK Sinar Nusantara \\ ${ }^{1)}$ rberliaan@gmail.com; ${ }^{2}$ hasbi@sinus.ac.id; ${ }^{3)}$ kustanto@sinus.ac.id
}

\begin{abstract}
A developing business must have a goal so that activities in a business can be directed. Later, the business can finally achieve these goals, it is necessary to have a careful plan to determine the production of products that are made to meet market needs. Therefore, this study aims to determine the optimization of the supply application system of broiler chicken at Boyolali Restaurant using the Fuzzy Tsukamoto method based on sales data and restaurant needs. Boyolali Restaurant also has a disadvantage, namely controlling the supply of chicken that is still not suitable and not optimal for each day due to the number of requests that continue to vary each day The number of produced products is something that influences competition in the business world. The type of data consists of Primary Data. There are 2 kinds of primary datain this research, namely: Observation Method, Interview Method and Secondary Data in the form of Library Studies. Data Analysis with system analysis used the Flowchart system, input output design, and system testing. The result of this study is making web applications using the PHP programming language with a MySQL database. The validity test by comparing the data of real chicken orders and the chicken order data from the results of fuzzy calculations from the application is valid. Comparison with the difference between real data and fuzzy calculation results with the highest difference order 347 pieces of chicken supply and the lowest difference of 3 pieces of chicken supply with an average difference in supply orders is 70 stocks of chicken pieces. Comparison of real order data with fuzzy results has accuracy above $70 \%$ with an accuracy average of $93 \%$.
\end{abstract}

Keywords: Optimization System, Chicken Stock, Fuzzy, PHP.

\section{PENDAHULUAN}

Permintaan pelanggan dalam waktu seminggu \pm 950 stok ayam potong yang terjual, sedangkan stok ayam potong yang disediakan \pm 900 stok ayam potong untuk dijual, dilihat dari persediaan dan penjualan yang sudah berjalan \pm 6 bulan, per minggu nya memiliki potensi kerugian dan potensi keuntungan jika dilihat dari jumlah stok ayam potong. Potensi kerugian dilihat dari per minggu nya ada persediaan stok ayam potong yang lebih banyak dari permintaan pelanggan, dan potensi keuntungan ada ketika permintaan lebih banyak dari persediaan stok ayam potong. Sehingga diperlukan suatu metode pengoptimalan yang tepat guna memudahkan dalam hal pendataan sehingga penggunaan stok ayam potong tidak terjadi kerugian dan dilakukan dengan optimal serta sesuai. Banyak cara yang dapat dilakukan untuk menentukan jumlah stok ayam potong yang optimal, salah satunya adalah menggunakan
Fuzzy. Dengan metode tersebut diharapkan dapat membantu usaha penjualan dalam menentukan jumlah stok atau jumlah produksi. Penelitian ini bertujuan untuk menentukan optimasi sistem aplikasi stok ayam potong pada Rumah Makan Boyolali menggunakan metode Fuzzy Tsukamoto berdasarkan data penjualan dan kebutuhan rumah makan.

Data yang dimiliki Rumah Makan Boyolali berupa data numerik, sehingga algoritma yang cocok dan memiliki akurasi pengoptimalan yang tinggi adalah algoritma fuzzy. Berdasarkan latar belakang tersebut, maka penulis memutuskan untuk mengajukan judul penelitian yaitu "Optimasi Stok Ayam Potong Menggunakan Metode Fuzzy Tsukamoto di Rumah Makan Boyolali”.

\section{TINJAUAN PUSTAKA}

Rumah makan menurut Peraturan Menteri Pariwisata Dan Ekonomi Kreatif Tentang Standar Usaha Rumah Makan Nomor 12 
Tahun 2014 tentang Standar Usaha Rumah Makan, dalam peraturan ini yang dimaksud dengan : "Usaha Rumah Makan adalah usaha penyediaan makanan dan minuman dilengkapi dengan peralatan dan perlengkapan untuk, penyimpanan dan penyajian di suatu tempat tetap yang tidak berpindah pindah dengan tujuan memperoleh keuntungan atau laba" [1].

Logika fuzzy adalah peningkatan dari logika Boolean oleh Lot fi Zadeh pada tahun 1965, berdasarkan pada teori matematika dari himpunan fuzzy, yang merupakan generalisasi teori himpunan klasik. Logika fuzzy menyediakan fleksibilitas yang sangat berguna untuk penalaran, yang memungkinkan untuk memperhitungkan ketidakakuratan dan ketidakpastian. Salah satu keuntungan logika fuzzy adalah untuk mengartikan penalaran manusia dengan aturan-aturan (rule) yang diatur dalam bahasa pernyataan implikasi [2]. Metode Tsukamoto adalah salah satu metode dari Fuzzy Inference System. Dalam metode ini, ia menggunakan aturan sebab-akibat atau "jika-maka". Metode penghitungan metode fuzzy Tsukamoto adalah aturan yang dibentuk mewakili fuzzy set, kemudian dihitung derajat keanggotaan sesuai dengan aturan yang telah dibuat. Setelah memperoleh tingkat keanggotaan, nilai alfa yang telah ditentukan (a) akan diperoleh dengan mencari nilai minimum dari fungsi keanggotaan. Kemudian, akan mencari nilai output yang merupakan nilai pasti yang disebut proses defuzzifikasi, yang dinyatakan dalam persamaan berikut. [3] Secara umum bentuk model fuzzy Tsukamoto adalah : If (X IS A) and (Y IS B) Then ( $Z$ IS C). Dimana $A, B$, dan $C$ adalah himpunan fuzzy. Dalam inferensinya, metode Tsukamoto menggunakan tahapan berikut :

1. Fuzzyfikasi

2. Pembentukan basis pengetahuan fuzzy (Rule dalam bentuk IF...THEN)

3. Mesin Inferensi menggunakan fungsi implikasi MIN, untuk mendapatkan nilai $\alpha$ predikat tiap-tiap rule ( $\alpha 1, \alpha 2, \alpha 3, \ldots . . \alpha n)$. Kemudian masing-masing nilai $\alpha$-predikat ini digunakan untuk menghitung keluaran hasil inferensi secara tegas (crisp) masing-masing rule (z1, z2, z3,.....zn)

4. Defuzzyfikasi menggunakan metode RataRata (Average) [4].

$$
\mathrm{Z}=\frac{\sum \alpha_{i} \mathrm{Z}_{1}}{\sum \alpha_{i}}
$$

Dimana:

$\alpha=$ alpha

$\mathrm{z}=$ nilai pasti

\section{$\mathrm{Z}=$ defuzzification}

Pada tahun 2013, Windu Gata menuturkan Unified Modeling Language (UML) adalah bahasa spesifikasi standar yang dipergunakan untuk mendokumentasikan, menspesifikasikan dan membangun perangkat lunak. UML merupakan metodologi dalam mengembangkan sistem berorientasi objek dan juga merupakan alat untuk mendukung pengembangan sistem [5].

PHP adalah bahasa pemrograman yang digunakan secara luas untuk penanganan pembuatan dan pengembangan sebuah web dan bias digunakan pada HTML. PHP merupakan singkatan dari "PHP : Hypertext Preprocessor", dan merupakan bahasa yang disertakan dalam dokumen HTML, sekaligus bekerja di sisi server (server-side HTMLembedded scripting). Artinya sintaks dan perintah yang diberikan akan sepenuhnya dijalankan di server tetapi disertakan pada halaman HTML biasa, sehingga script-nya tak tampak disisi client [6].

MySQL, sistem manajemen basis data Open Source SQL yang paling populer, dikembangkan, didistribusikan, dan didukung oleh Oracle Corporation. Database adalah kumpulan data terstruktur. Untuk menambah, mengakses, dan memproses data yang disimpan dalam database komputer, diperlukan sistem manajemen basis data seperti Server MySQL. Karena komputer sangat baik dalam menangani sejumlah besar data, sistem manajemen basis data memainkan peran sentral dalam komputasi, sebagai utilitas yang berdiri sendiri, atau sebagai bagian dari aplikasi lain. Bagian SQL dari "MySQL" adalah singkatan dari "Structured Query Language" [7]

MySQL merupakan database yang awalnya hanya berjalan pada sistem Unix dan Linux. Seiring berjalannya waktu dan banyaknya peminat yang menggunakan database ini, MySQL merilis versi yang dapat diinstal pada hampir semua platform, termasuk Windows. Lisensi dari MySQL adalah freeware [8].

XAMPP adalah perangkat lunak bebas, yang mendukung banyak sistem operasi, merupakan kompilasi dari beberapa program. Fungsinya adalah sebagai server yang berdiri sendiri (localhost), yang terdiri atas program Apache HTTP Server, MySQL database, dan penerjemah bahasa yang ditulis dengan bahasa pemrograman PHP dan Perl. Nama XAMPP merupakan singkatan dari $X$ (empat sistem operasi apapun), Apache, MySQL, PHP 
dan Perl. Program ini tersedia dalam GNU (General Public License) dan bebas, merupakan web server yang mudah digunakan yang dapat melayani tampilan halaman web yang dinamis [9].

Validitas menunjukan derajat ketepatan antara data yang sesungguhnya terjadi pada objek dengan data yang dikumpulkan oleh. Untuk mencari validitas sebuah item, kita mengkorelasikan skor item dengan total itemitem tersebut. Jika koefisien antara item dengan total item sama atau diatas 0,3 maka item tersebut dinyatakan valid, tetapi jika nilai korelasinya dibawah 0,3 maka item tersebut dinyatakan tidak valid [10].

Ketidaktepatan jumlah produksi sangat berpengaruh terhadap tingkat kerugian yang diakibatkan kurangnya pekerja, karena jumlah produksi barang yang terlalu rendah ataupun berlebihan. Masalah ini bisa diselesaikan dengan mengembangkan sebuah aplikasi dalam sistem pendukung keputusan dan teknik yang dapat diterapkan dalam mengembangkan sistem pendukung keputusan ini adalah Fuzzy Tsukamoto. Dalam penelitian ini dibuktikan dengan tabel perbandingan antara perhitungan manual dengan perhitungan sistem, dan didapatkan hasil persentase kebenaran dari sistem ini adalah sebesar $96 \%$ [11].

Terdapat ketidaksesuaian antara rencana produksi perusahaan dengan jumlah permintaan konsumen yang menyebabkan terjadinya kelebihan stok (overstock), hal ini menyebabkan stok kopi bubuk dan sangrai menjadi bertambah. Maka diperlukan proses rencana produksi menggunakan kecerdasan buatan, salah satu metode yang dapat digunakan adalah Fuzzy Logic (logika fuzzy). Hasil prediksi jumlah produksi kopi bubuk dan sangrai menggunakan metode fuzzy Tsukamoto berdasarkan data permintaan dan stok di PDP Kahyangan Jember satu tahun terakhir menghasilkan nilai MAPE sebesar $16 \%$. Nilai MAPE yang diperoleh dikatakan "baik" karena berada diantara 10-20\% [12].

Pengendalian stok gudang merupakan satu kegiatan yang dilakukan dalam sebuah perusahaan dan khususnya pada CV. Rejeki Mulya Jaya yang bergerak di bidang jasa kontraktor. Oleh karna itu, dalam pengembangan sistem ini bertujuan untuk menerapkan aplikasi yang menggunakan metode fuzzy Tsukamoto untuk mengoptimisasikan jumlah pengambilan bahan perusahaan berdasarkan data gudang dan kebutuhan perusahaan. Berdasarkan dari hasil pengujian aplikasi maka dapat diketahui bahwa pengoptimisasian jumlah pengambilan bahan dari penggunaan metode fuzzy tsukamoto sebagian besar dapat memenuhi kebutuhan yang ada. Dengan menggunakan aplikasi ini pihak perusahaan dapat mengambil keputusan lebih cepat dari perhitungan manual [13].

Permasalahan yang sering ditemukan disetiap akhir bulan pada tempat usaha roti canai ialah penentuan kelayakan karyawan yang akan mendapat reward, dikerenakan belum adanya sebuah sistem sebagai alat bantu dalam pengambilan keputusan secara tepat. Maka digunakanlah Sistem Pendukung Keputusan yaitu metode fuzzy logic Tsukamoto. Hasil penelitian ini dalam penentuan reward akan ditentukan setiap akhir bulan, dengan bertujuan untuk meningkat kualitas kinerja karyawan, maksud reward disini ialah berupa uang yang akan diberikan pada tiap-tiap karyawan setelah melakukan penilaian berdasar kualitas yang dimiliki. Penilaian yang digunakan yaitu "TIDAK DAPAT" , "DIPERTIMBANGKAN" dan "DAPAT", pemberian reward ini akan disesuai dengan keadaan serta kualitas yang dimiliki sehingga reward dapat diberikan kepada karyawan secara objektif [14].

Jepang merupakan negara yang permintaan sepatu kulitnya cukup tinggi, agar nilai ekspor sepatu kulit Indonesia ke Jepang dapat maksimal, diperlukan suatu metode yang dapat memprediksi nilai ekspor sepatu kulit Indonesia ke Jepang. Salah satu metode yang dapat digunakan adalah metode logika fuzzy, metode yang dapat digunakan dalam pengaplikasian logika fuzzy adalah metode Mamdani, Sugeno, dan Tsukamoto. Hasil penelitian menunjukkan bahwa metode Mamdani merupakan metode terbaik dibandingkan dengan metode Sugeno dan Tsukamoto. Metode Mamdani memiliki hasil yang paling dekat dengan hasil sebenarnya dengan tingkat error $7 \%$, sehingga metode Mamdani bisa dijadikan metode yang direkomendasikan dalam memprediksi jumlah optimal ekspor HS 6403 Indonesia ke Jepang dibandingkan metode Sugeno yang persentase erromya $32 \%$, dan metode Tsukamoto dengan persentase erromya $19,5 \%[15]$.

\section{METODE PENELITIAN}

Metodologi penelitian yang digunakan skripsi ini adalah Metode Pengumpulan Data, 
Desain Sistem, Pengujian Sistem dan Kontruksi atau Implementasi Sistem.

\subsection{Analisa Sistem}

Pada tahap ini pengumpulan data dilakukan dengan wawancara kepada karyawan, membuat kuisoner, observasi dan studi pustaka. Sedangkan sumber data yang diperoleh merupakan data primer dan data sekunder. Beberapa analisa yang digunakan penulis sebagai berikut :

1. Pengumpulan Data

Dalam pengumpulan data penulis menggunakan 3 cara yaitu, interview, observasi, dan studi pustaka :

a. Interview

Peneliti mengumpulkan data dengan mengajukan pertanyaan yang berkaitan dengan penelitian penentuan jumlah stok ayam kepada pemilik Rumah Makan Boyolali serta para karyawan/i.

b. Observasi

Terjun langsung ke Rumah Makan Boyolali. Dengan cara observasi ini akan diperoleh data yang lengkap dan valid. Selain itu, metode observasi mempunyai kelebihan, yaitu peneliti mengetahui sendiri dengan jelas tentang proses memprediksi produksi berdasarkan kriteria-kriteria yang ada.

c. Studi Pustaka

Informasi itu dapat diperoleh dari buku-buku ilmiah, dan peraturan-peraturan, karangan ilmiah, laporan penelitian, ketetapanketetapan, dan literatur lainnya. Untuk memperkuat analisa penulis juga mencari informasi dengan membaca buku dan literatur yang terdapat pada perpustakaan.

\section{Sumber Data}

Sumber data terkumpul melalui pengumpulan data dan akan dianalisis dengan berfokus pada fungsi sistem informasi dan manajemen sumber data berasal dari data primer dan data sekunder.

\section{a. Data Primer}

Data primer yang penulis ambil berupa data penjualan, order per minggu, standar penggunaan stok ayam potong.

b. Data Sekunder

Data sekunder yang penulis ambil berupa jurnal penelitian, buku, artikel, laporan dan sumber yang lainnya.

\subsection{Pengujian Sistem}

Uji Validitas

Uji yang digunakan untuk seberapa akurat sistem dapat melakukan pekerjaan dibandingkan secara manual dan riil, akan diperoleh berapa persen keakuratan dari uji sistem yang dijalankan.

\subsection{Konstruksi atau Implementasi Sistem}

Untuk membuat sebuah sistem optimasi dari tahap awal pembuatan sampai tahap pengujian sistem. Pada tahap ini menggunakan bahasa pemrograman PHP sehingga nantinya aplikasi optimasi ini berupa aplikasi web dan Database MySQL. Aplikasi desktop yang digunakan ialah XAMPP sebagai Virtual Server.

\section{HASIL DAN PEMBAHASAN \\ 4.1. Aturan Perhitungan}

Terdapat 3 (tiga) langkah untuk memperkirakan jumlah order ayam potong yaitu mendefinisikan variabel yang ada dan sesuai, inferensi sistem, dan melakukan defuzzifikasi atau menentukan output, berikut tabel yang melengkapi aturan perhitungan berdasarkan data dari Boyolali, yaitu Tabel 1 berisi Data Penjualan, Tabel 2 berisi Semesta Pembicaraan, Tabel 3 berisi Himpunan Input dan Tabel 4 berisi Himpunan Output.

\section{Tabel 1. Data Penjualan}

\begin{tabular}{|l|l|}
\hline \multicolumn{1}{|c|}{ Data } & \multicolumn{1}{c|}{ Jumlah Ayam Potong } \\
\hline Terjual Minimum & 500 Min. Terjual \\
\hline Terjual Maksimum & 1200 Maks. Terjual \\
\hline Sisa Minimum & 5 Min. Tersisa \\
\hline Sisa Maksimum & 200 Maks. Tersisa \\
\hline Order Minimum & 500 Min. Order \\
\hline Order Maksimum & 1300 Maks. Order \\
\hline
\end{tabular}

Tabel 2. Semesta Pembicaraan

\begin{tabular}{|c|c|c|c|}
\hline Fungsi & Variabel & Notasi & $\begin{array}{c}\text { Semesta } \\
\text { Pembicaraan }\end{array}$ \\
\hline \multirow{2}{*}{ Input } & Terjual & $\mathrm{Te}$ & $500-1200$ \\
\cline { 2 - 4 } & Sisa & $\mathrm{Si}$ & $5-200$ \\
\hline Output & Order & $\mathrm{Or}$ & $500-1300$ \\
\hline
\end{tabular}

Tabel 3. Himputan Input

\begin{tabular}{|c|c|c|c|c|}
\hline \multicolumn{2}{|c|}{ Variabel } & \multicolumn{2}{c|}{$\begin{array}{c}\text { Himpunan Input } \\
\text { Fuzzy }\end{array}$} & \multirow{2}{*}{ Domain } \\
\hline Nama & Notasi & Nama & Notasi & \\
\hline \multirow{2}{*}{ Terjual } & \multirow{2}{*}{$\mathrm{Te}$} & Sedikit & Se & $500-700$ \\
\cline { 3 - 5 } & & Banyak & $\mathrm{Ba}$ & $\begin{array}{c}700- \\
1200\end{array}$ \\
\hline \multirow{2}{*}{ Sisa } & \multirow{2}{*}{$\mathrm{Si}$} & Sedikit & $\mathrm{Se}$ & $5-195$ \\
\cline { 3 - 4 } & Banyak & $\mathrm{Ba}$ & $195-200$ \\
\hline
\end{tabular}

Tabel 4. Himpunan Output

\begin{tabular}{|c|c|c|c|c|}
\hline \multicolumn{2}{|c|}{ Variabel } & \multicolumn{2}{c|}{$\begin{array}{c}\text { Himpunan Output } \\
\text { Fuzzy }\end{array}$} & \multirow{2}{*}{ Domain } \\
\hline Nama & Notasi & Nama & Notasi & \\
\hline \multirow{2}{*}{ Order } & \multirow{2}{*}{ Or } & Sedikit & Se & $500-800$ \\
\cline { 3 - 5 } & & Banyak & Ba & $800-$ \\
& & & 1300 \\
\hline
\end{tabular}

Dalam melakukan penghitungan stok dengan metode Fuzzy Tsukamoto yang dibutuhkan himpunan keanggotaan fuzzy 
untuk setiap variabel. Terdapat 3 variabel yang menjadi kriteria dalam pengoptimasian ini yaitu Terjual, Sisa dan Order. Adapun himpunan fuzzy pada setiap variabel dijelaskan sebagai berikut:

\section{Variabel Terjual}

Fungsi keanggotaan variabel terjual direpresentasikan pada gambar berikut, lihat di Gambar 1. Fungsi Keanggotaan Variabel Terjual.

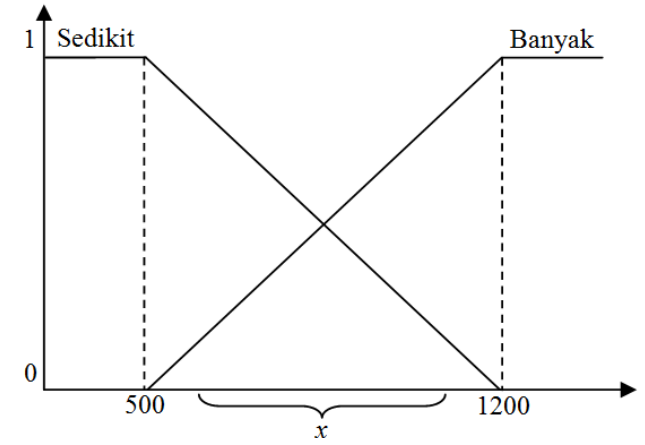

Gambar 1. Fungsi Keanggotaan Variabel Terjual

$T e \_s e[x]= \begin{cases}1, & ; x \leq 500 \\ \frac{1200-x}{700}, & ; 500 \leq x \leq 1200 \\ 0, & ; x \geq 1200 \ldots \ldots\end{cases}$

$T e \_b a[x]= \begin{cases}0, & ; x \leq 500 \\ \frac{x-500}{700}, & ; 500 \leq x \leq 1200 \\ 1, & ; x \geq 1200 \ldots \ldots\end{cases}$

Keterangan $:$ Te_se $=$ Terjual Sedikit, Te_ba $=$ Terjual Banyak, $a=$ Data Terjual Sedikit, $b=$ Data Terjual Banyak.

\section{Variabel Sisa}

Fungsi keanggotaan variabel sisa direpresentasikan pada gambar berikut, lihat di Gambar 2. Fungsi Keanggotaan Variabel Sisa.

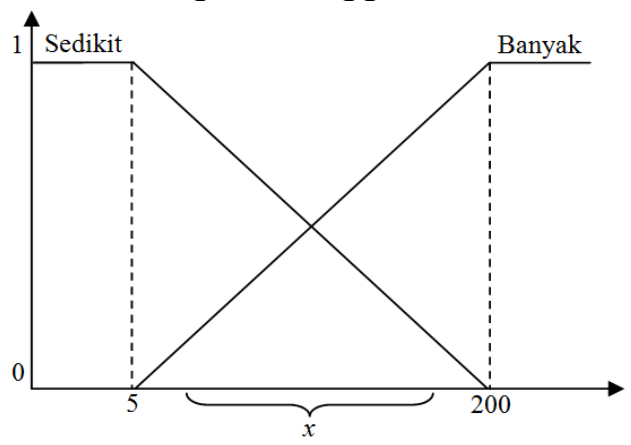

Gambar 2. Fungsi Keanggotaan Variabel Sisa.

Si_se $[x]= \begin{cases}1, & ; x \leq 5 \\ \frac{200-x}{195}, & ; 5 \leq x \leq 200 \\ 0, & ; x \geq 200 \ldots\end{cases}$

$78\left\{\begin{array}{l}0 \\ \end{array}\right.$

$\begin{array}{cl}\text { Si_ba }[x]=\frac{x-5}{195}, & ; 5 \leq x \leq 200 \\ 1, & ; x \geq 200 \ldots .\end{array}$

Keterangan $:$ Si_se $=$ Sisa Sedikit, Si_ba $=$ Sisa Banyak, $a=$ Data Sisa Sedikit, $b=$ Data Sisa Banyak.

3. Variabel Order

Fungsi keanggotaan variabel order direpresentasikan pada gambar berikut, lihat di Gambar 3. Fungsi Keanggotaan Variabel Order.

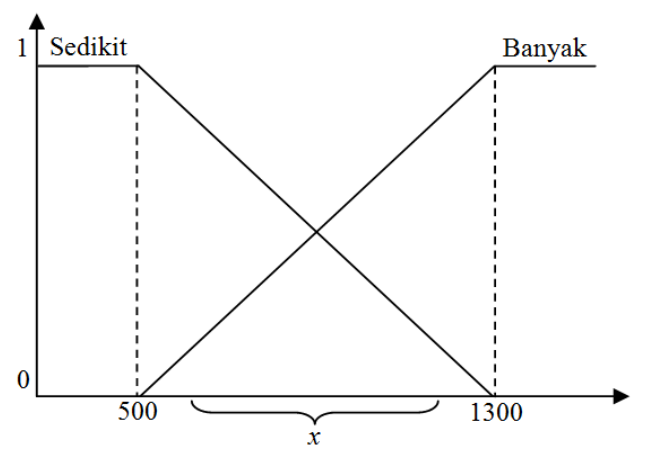

Gambar 3. Fungsi Keanggotaan Variabel Order

$$
\begin{aligned}
& \text { Or_se }[x]= \begin{cases}1, & ; x \leq 500 \\
\frac{1300-x}{800}, & ; 500 \leq x \leq 1300 \\
0, & ; x \geq 1300 \ldots \ldots\end{cases} \\
& \text { Or_ba }[x]= \begin{cases}0, & ; x \leq 500 \\
\frac{x-500}{800}, & ; 500 \leq x \leq 1300 \\
1, & ; x \geq 1300 \ldots \ldots\end{cases}
\end{aligned}
$$

Keterangan : Or_se $=$ Order Sedikit , Or_ba $=$ Order Banyak, $\mathrm{a}=$ Data Order Sedikit, $\mathrm{b}=$ Data Order Banyak.

\subsection{Studi Kasus}

1. Dari data Boyolali pada minggu ke-2, memiliki data penjualan sebanyak 1000 ayam potong yang terjual, dan memiliki sisa stok sebanyak 90 ayam potong. Hitung dengan menggunakan metode Tsukamoto, berapa banyak jumlah ayam potong yang harus diorder untuk 1 minggu ?

\section{Penyelesaian :}

Tahap Ke-1 : Fuzzifikasi

1. Terjual; terdiri atas 2 himpunan fuzzy, yaitu SEDIKIT dan BANYAK (Gambar 1).

Derajat keanggotaan untuk terjual 943 ayam potong adalah :

$$
\begin{aligned}
\mu T e \_s e[1000] & =(1200-1000) / 700 \\
& =0,28 \\
\mu T e \_b a[1000] & =(1000-500) / 700 \\
& =0,71
\end{aligned}
$$

2. Sisa; terdiri atas 2 himpunan fuzzy, yaitu SEDIKIT dan BANYAK (Gambar 2) 
Derajat keanggotaan untuk sisa 90 ayam potong adalah :

$$
\begin{aligned}
\mu S i \text { se }[90] & =(200-90) / 195 \\
& =0,56 \\
\mu S i \text { ba }[90 & =(90-5) / 195 \\
& =0,43
\end{aligned}
$$

3. Order; terdiri atas 2 himpunan fuzzy, yaitu SEDIKIT dan BANYAK (Gambar 3)

Tahap Ke-2 : Pembentukan Rule

[R1] IF terjual BANYAK And sisa SEDIKIT THEN order BANYAK.

[R2] IF terjual SEDIKIT And sisa BANYAK THEN order SEDIKIT.

[R3] IF terjual SEDIKIT And sisa SEDIKIT THEN order BANYAK.

[R4] IF terjual BANYAK And sisa BANYAK THEN order SEDIKIT.

Tahap Ke-3 : Fuzzy Inference System

[R1] IF terjual BANYAK And sisa SEDIKIT THEN order BANYAK

$\alpha 1=\mu \mathrm{Te} \_b a \cap \mu \mathrm{Si} \_s e$

$$
=\min \left(\mu \mathrm{Te} \_ \text {ba }[0,71], \mu S i \_s e[0,56]\right)
$$$$
=0,56
$$

Himpunan BANYAK pada grafik keanggotaan variabel order (Gambar 3), $(z-500) / 800=0,561$ $z 1=951,28$

[R2] IF terjual SEDIKIT And sisa BANYAK THEN order SEDIKIT

$\alpha 2=\mu T e \_$se $\cap \mu S i \_b a$

$$
=\min \left(\mu \mathrm{Te} \text { _se }[0,28], \mu \mathrm{Si} \_b a[0,43]\right)
$$$$
=0,28
$$

Himpunan SEDIKIT pada grafik keanggotaan variabel order (Gambar 3), $(1300-z) / 800=0,28$ $\mathrm{z} 2=1071,42$

[R3] IF terjual SEDIKIT And sisa SEDIKIT THEN order BANYAK

$$
\begin{aligned}
\alpha 3 & =\mu T \text { Te_se } \cap \mu \mathrm{Si} \text { se } \\
& =\min (\mu \mathrm{Te} \text { _se }[0,28], \mu \mathrm{Si} \text { se }[0,56]) \\
& =0,28
\end{aligned}
$$

Himpunan BANYAK pada grafik keanggotaan variabel order (Gambar 3), $(z-500) / 800=0,28$ $\mathrm{z} 3=728,57$

[R4] IF terjual BANYAK And sisa BANYAK THEN order SEDIKIT

$\alpha 4=\mu \mathrm{Te} \_$ba $\cap \mu \mathrm{Si} \_b a$ $=\min \left(\mu \mathrm{Te} \_\right.$ba $[0,71], \mu \mathrm{Si} \_$ba $\left.[0,43]\right)$ $=0,43$

Himpunan SEDIKIT pada grafik keanggotaan variabel order (Gambar 3), $(1300-z) / 800=0,43$

$$
z 4=951,28
$$

Tahap Ke-4 : Defuzzifikasi

$Z=\frac{(\alpha 1 * z 1)+(\alpha 2 * z 2)+(\alpha 3 * z 3)+(\alpha 4 * z 4)}{\alpha 1+\alpha 2+\alpha 3+\alpha 4}$

$\mathrm{Z}=$

$(0,56 * 951,28)+(0,28 * 1071,42)+(0,28 * 728,57)+(0,43 * 951,28)$ $0,56+0,28+0,28+0,43$

$$
Z=\frac{1445,76}{1,55}
$$$$
Z=933
$$

Jadi, jumlah ayam potong yang harus diorder untuk 1 minggu sebanyak 933 ayam potong.

\subsection{Perancangan Sistem}

4.3.1 Sistem Yang Akan Dijalankan

Sistem yang akan dijalankan dengan metode Fuzzy yaitu pencatatan data stok kemudian perencanaan order dan diproses dengan menggunakan metode fuzzy dan hasil analisa akan menentukan tindak lanjut yang dijalankan order atau tidak order. Lihat diagram alir dibawah ini, Diagram Alir (Flowchart) lihat pada Gambar 4. Diagram Alir Dengan Metode Fuzzy.

\subsubsection{Use case diagram}

Use case diagram adalah Sebuah model logis yang menggambarkan sistem secara formal mewakili bagaimana bisnis berinteraksi dengan lingkungannya. Dalam use case diagram ini terdapat beberapa actor antara lain:

1) Koki

Koki yang bertugas mengelola proses perhitungan, dan mengelola laporan stok ayam potong

\section{2) Kasir}

Sebagai admin proses mengelola data Produk, data kriteria, Stok, Login dan laporan.

3) Owner RM

Owner RM bertugas untuk mengelola data user dan laporan rekap hasil. Seperti tampak pada Gambar 5, Usecase diagram Fuzzy Optimasi Stok Ayam Potong, alur sistem dimulai dari user dengan mengakses login kemudian akan masuk sistem optimasi stok metode fuzzy tsukamoto, setiap user akan mengakses data Produk, stok, proses fuzzy dan melihat hasil. 


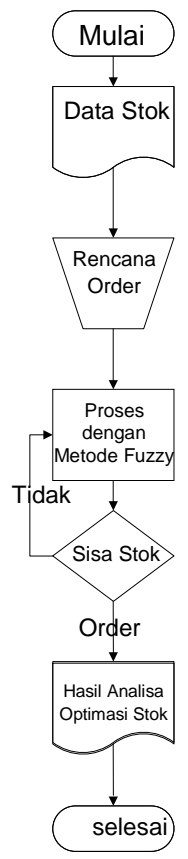

Gambar 4. Diagram Alir Dengan Metode Fuzzy

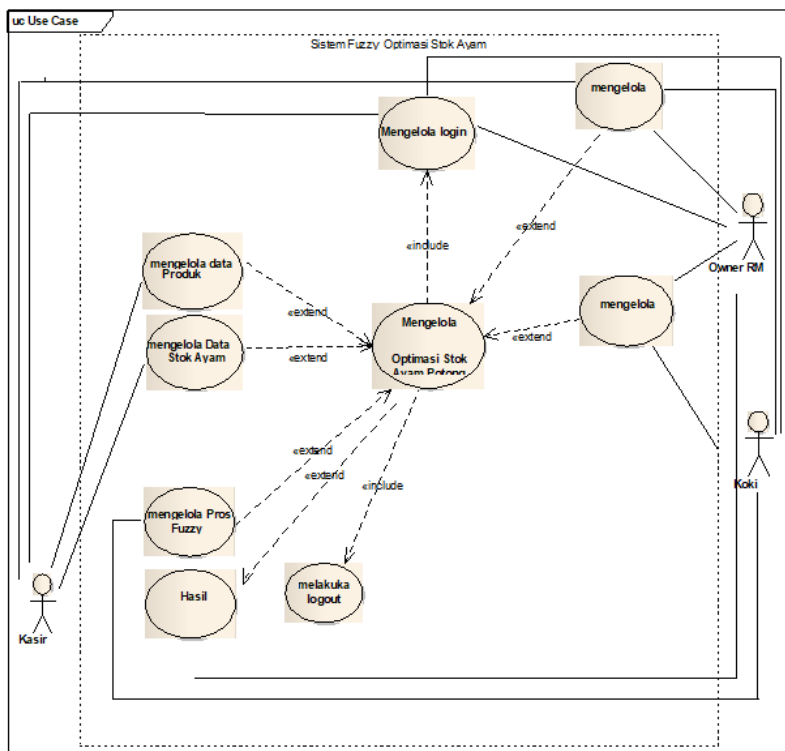

Gambar 5. Use case Diagram Fuzzy Optimasi Stok Ayam Potong

\section{a. Use Case Realization Mengelola Proses} fuzzy

Seperti tampak dalam Gambar 6. use case realization mengelola proses fuzzy menggambarkan hubungan antara Kasir sebagai aktor pendata proses fuzzy dengan sistem dalam menginputkan sebuah password yang dapat digunakan untuk login ke sistem.

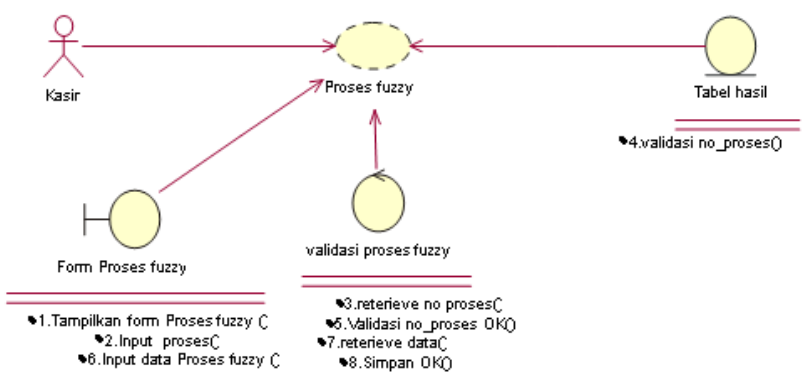

Gambar 6. Use Case Realization Mengelola Proses Fuzzy

1. Class diagram

Class adalah sebuah spesifikasi yang jika diinstansiasi akan menghasilkan sebuah objek dan merupakan inti dari pengembangan dan desain berorientasi objek. Seperti pada Gambar 7. Class Diagram Fuzzy Optimasi Stok, Class menggambarkan keadaan (atribut/properti) suatu sistem, sekaligus menawarkan layanan untuk memanipulasi keadaan tersebut (metoda/fungsi). Menggambarkan struktur dan deskripsi class, package dan objek beserta hubungan satu sama lain seperti containment, pewarisan, asosiasi dan lain-lain. Hubungan yang digunakan dari User ke Login yaitu 1 user 1 login, User ke Laporan yaitu 1 user banyak laporan, Stok ke Proses yaitu 1 stok untuk 1 proses, Produk ke Proses yaitu banyak Produk untuk 1 Proses.

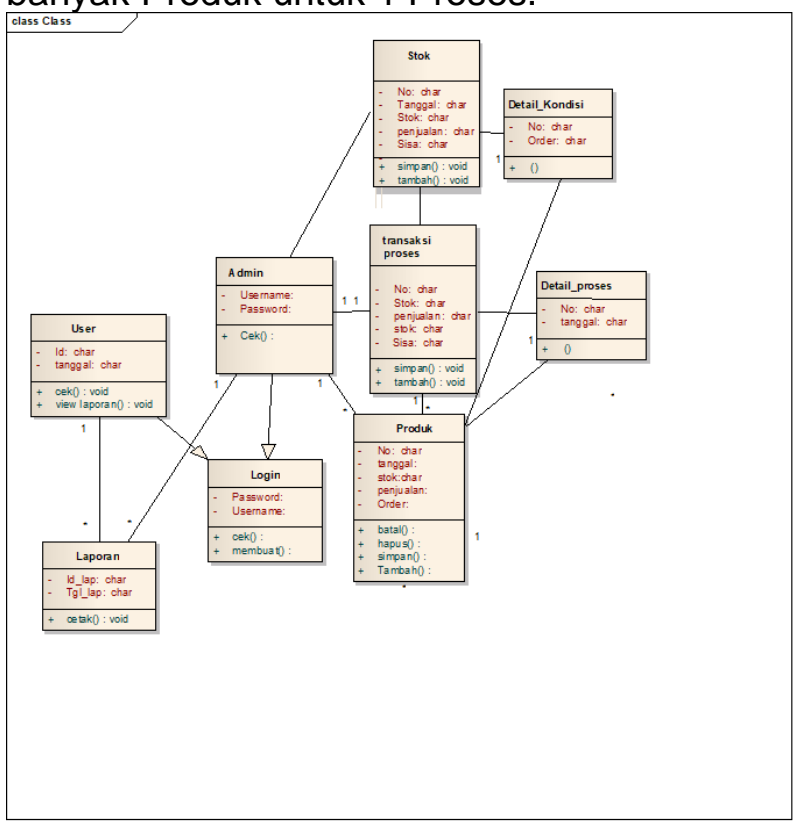

Gambar 7. Class Diagram Fuzzy Optimasi Stok

2. Activity Diagram

Activity diagram Transaksi Proses fuzzy

Proses dilakukan Setelah menampilkan menu transaksi proses fuzzy kemudian user akan memasukan no_proses, tgl_proses, Stok, Stok, penjualan, sisa, kriteria. Jika user telah 
selesai mengisi data maka sistem akan menampilkan tabel data Produk masuk sesuai data yang diinput.

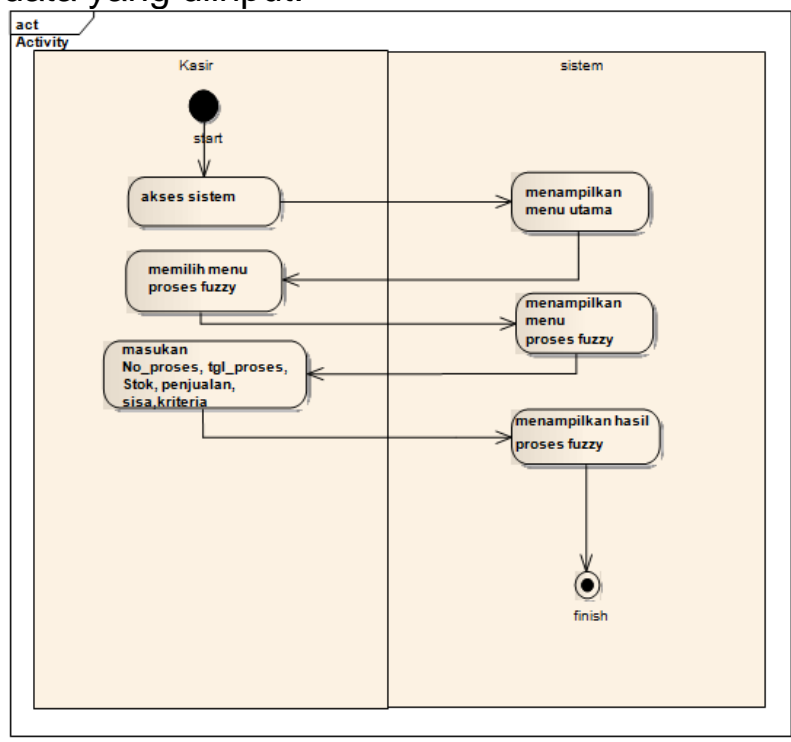

Gambar 8. Activity Diagram Transaksi Proses Fuzzy

\section{Interaction Sequence Diagram}

Interaction sequence diagram Transaksi Proses fuzzy. Dalam sequence ini terdapat satu class actor yang dapat melakukan login yaitu bagian proses fuzzy. Dan terdapat dua class boundary yaitu halaman menu utama dan halaman menu kelola transaksi proses fuzzy. Terdapat satu class control yaitu proses kelola transaksi proses fuzzy serta terdapat satu class entity yaitu tabel proses fuzzy.

Prosedur proses fuzzy adalah sebagai berikut: Bagian proses fuzzy mengakses sistem dengan memilih menu Transaksi pada menu utama, kemudian pilih Transaksi Proses fuzzy, setelah itu sistem akan menampilkan menu melakukan transaksi proses fuzzy. Tahap selanjutnya adalah mengisi data Produk yang sudah masuk (set no_proses, tgl_proses, No, Stok, penjualan). Jika sudah selesai sistem akan memasukkan semua data yang di input ke dalam tabel proses fuzzy, seperti pada Gambar 9. Sequence diagram Transaksi Proses fuzzy.

\subsubsection{Menjalankan Program}

Cara menjalankan program aplikasi ini dapat dilakukan dengan banyak cara: Menggunakan File Mozilla ketik (Localhost/fuzzy).

3. Master Proses Perhitungan.

Untuk menjalankan Proses Perhitungan klik menu Proses. Muncul isian proses perhitungan, Proses berjalan otomatis, setelah selesai klik SIMPAN, seperti pada Gambar 10. Tampilan Proses Perhitungan.

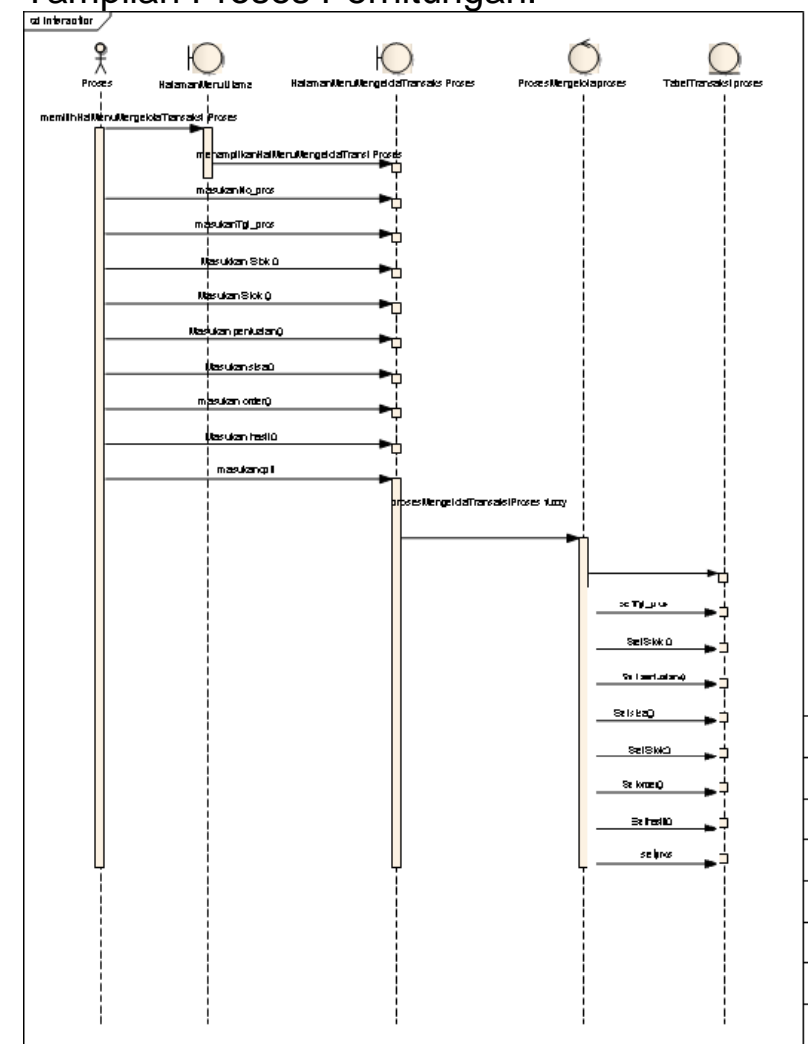

Gambar 9. Sequence diagram Transaksi Proses fuzzy

\section{Gambar 10. Tampilan Proses Perhitungan}

\subsubsection{Pengujian Sistem}

Pengujian validitas program digunakan untuk mengetahui Sistem optimasi stok dengan Metode Tsukamoto valid atau tidak. Aplikasi diperoleh dari Implementasi Program yang telah dibuat. Sehingga dapat diketahui tingkat akurasi optimasi stok dengan metode.

Tabel 5. Hasil Perhitungan Dengan Aplikasi

\begin{tabular}{|c|c|c|}
\hline Minggu Ke - & \multicolumn{2}{|c|}{ } \\
\hline $\mathrm{Ke}-1$ & 952,7903 & 953 \\
\hline $\mathrm{Ke}-2$ & 932,6340 & 933 \\
\hline $\mathrm{Ke}-3$ & 972,7723 & 973 \\
\hline $\mathrm{Ke}-4$ & 1075,7940 & 1076 \\
\hline $\mathrm{Ke}-5$ & 995,0443 & 995 \\
\hline $\mathrm{Ke}-6$ & 966,9908 & 967 \\
\hline $\mathrm{Ke}-7$ & 1008,2825 & 1008 \\
\hline $\mathrm{Ke}-8$ & 1018,6582 & 1019 \\
\hline
\end{tabular}




\begin{tabular}{|c|c|c|}
\hline Minggu Ke - & \multicolumn{2}{|c|}{ } \\
\hline $\mathrm{Ke}-9$ & 1036,4103 & 1036 \\
\hline $\mathrm{Ke}-10$ & 1125,4025 & 1125 \\
\hline $\mathrm{Ke}-11$ & 977,4975 & 977 \\
\hline $\mathrm{Ke}-12$ & 972,1424 & 972 \\
\hline $\mathrm{Ke}-13$ & 963,4188 & 963 \\
\hline $\mathrm{Ke}-14$ & 980,8314 & 981 \\
\hline $\mathrm{Ke}-15$ & 945,0161 & 945 \\
\hline $\mathrm{Ke}-16$ & 849,0359 & 849 \\
\hline $\mathrm{Ke}-17$ & 949,9189 & 950 \\
\hline $\mathrm{Ke}-18$ & 827,1048 & 827 \\
\hline $\mathrm{Ke}-19$ & 827,1048 & 827 \\
\hline $\mathrm{Ke}-20$ & 972,4647 & 972 \\
\hline $\mathrm{Ke}-21$ & 1016,2265 & 1016 \\
\hline $\mathrm{Ke}-22$ & 921,8887 & 922 \\
\hline $\mathrm{Ke}-23$ & 965,8120 & 966 \\
\hline $\mathrm{Ke}-24$ & 971,7949 & 972 \\
\hline $\mathrm{Ke}-25$ & 954,9282 & 955 \\
\hline $\mathrm{Ke}-26$ & 916,0256 & 916 \\
\hline $\mathrm{Ke}-27$ & 868,5110 & 869 \\
\hline $\mathrm{Ke}-28$ & 838,0535 & 838 \\
\hline $\mathrm{Ke}-29$ & 956,1305 & 956 \\
\hline $\mathrm{Ke}-30$ & 943,2248 & 943 \\
\hline $\mathrm{Ke}-31$ & 811,7173 & 812 \\
\hline $\mathrm{Ke}-32$ & 823,3154 & 823 \\
\hline $\mathrm{Ke}-33$ & 825,5868 & 826 \\
\hline $\mathrm{Ke}-34$ & 825,5868 & 826 \\
\hline $\mathrm{Ke}-35$ & 836,3385 & 836 \\
\hline $\mathrm{Ke}-36$ & 981,8713 & 982 \\
\hline $\mathrm{Ke}-37$ & 958,7413 & 959 \\
\hline $\mathrm{Ke}-38$ & 869,0771 & 869 \\
\hline $\mathrm{Ke}-39$ & 980,2413 & 980 \\
\hline $\mathrm{Ke}-41$ & 948,2984 & 948 \\
\hline $\mathrm{Ke}-42$ & 948,2984 & 948 \\
\hline $\mathrm{Ke}-43$ & 938,4805 & 938 \\
\hline $\mathrm{Ke}-44$ & 835,0274 & 914 \\
\hline $\mathrm{Ke}-46$ & 913,1624 & 836 \\
\hline $\mathrm{Ke}-47$ & 838,7703 & 839 \\
\hline $\mathrm{Ke}-49-50$ & 866,4626 & 866 \\
\hline & 835,9283 & 847 \\
\hline & & 835 \\
\hline
\end{tabular}

diharapkan. Semua fungsi pada aplikasi dapat berjalan dengan baik.

Tabel 6. Perbandingan

\begin{tabular}{|c|c|c|c|c|}
\hline No. & $\begin{array}{l}\text { Pehitung } \\
\text { an Riil } \\
\text { Order } \\
\text { (Ayam } \\
\text { Potong) }\end{array}$ & $\begin{array}{l}\text { Perhitungan } \\
\text { Metode } \\
\text { Fuzzy Order } \\
\text { (Ayam } \\
\text { Potong) }\end{array}$ & $\begin{array}{l}\text { Selisih } \\
\text { (Ayam } \\
\text { Potong) }\end{array}$ & $\begin{array}{c}\text { Akur } \\
\text { asi }\end{array}$ \\
\hline $\mathrm{Ke}-1$ & 1300 & 952,7903 & 347,2097 & $73 \%$ \\
\hline $\mathrm{Ke}-2$ & 1000 & 932,6340 & 67,3660 & $93 \%$ \\
\hline $\mathrm{Ke}-3$ & 850 & 972,7723 & 122,7723 & $87 \%$ \\
\hline $\mathrm{Ke}-4$ & 1060 & 1075,7940 & 15,7940 & $99 \%$ \\
\hline $\mathrm{Ke}-5$ & 1000 & 995,0443 & 4,9557 & $99 \%$ \\
\hline $\mathrm{Ke}-6$ & 950 & 966,9908 & 16,9908 & $98 \%$ \\
\hline $\mathrm{Ke}-7$ & 950 & 1008,2825 & 58,2825 & $94 \%$ \\
\hline $\mathrm{Ke}-8$ & 1000 & 1018,6582 & 18,6582 & $98 \%$ \\
\hline $\mathrm{Ke}-9$ & 1060 & 1036,4103 & 23,5897 & $98 \%$ \\
\hline $\mathrm{Ke}-10$ & 1100 & 1125,4025 & 25,4025 & $98 \%$ \\
\hline $\mathrm{Ke}-11$ & 1100 & 977,4975 & 122,5025 & $89 \%$ \\
\hline $\mathrm{Ke}-12$ & 925 & 972,1424 & 47,1424 & $95 \%$ \\
\hline $\mathrm{Ke}-13$ & 960 & 963,4188 & 3,4188 & $99 \%$ \\
\hline $\mathrm{Ke}-14$ & 930 & 980,8314 & 50,8314 & $95 \%$ \\
\hline $\mathrm{Ke}-15$ & 950 & 945,0161 & 4,9839 & $99 \%$ \\
\hline $\mathrm{Ke}-16$ & 900 & 849,0359 & 50,9641 & $94 \%$ \\
\hline $\mathrm{Ke}-17$ & 800 & 949,9189 & 149,9189 & $84 \%$ \\
\hline $\mathrm{Ke}-18$ & 980 & 827,1048 & 152,8952 & $84 \%$ \\
\hline $\mathrm{Ke}-19$ & 800 & 827,1048 & 27,1048 & $97 \%$ \\
\hline $\mathrm{Ke}-20$ & 800 & 972,4647 & 172,4647 & $82 \%$ \\
\hline $\mathrm{Ke}-21$ & 1000 & 1016,2265 & 16,2265 & $98 \%$ \\
\hline $\mathrm{Ke}-22$ & 1100 & 921,8887 & 178,1113 & $84 \%$ \\
\hline $\mathrm{Ke}-23$ & 930 & 965,8120 & 35,8120 & $96 \%$ \\
\hline $\mathrm{Ke}-24$ & 1000 & 971,7949 & 28,2051 & $97 \%$ \\
\hline $\mathrm{Ke}-25$ & 900 & 954,9282 & 54,9282 & $94 \%$ \\
\hline $\mathrm{Ke}-26$ & 900 & 916,0256 & 16,0256 & $98 \%$ \\
\hline $\mathrm{Ke}-27$ & 1000 & 868,5110 & 131,4890 & $87 \%$ \\
\hline $\mathrm{Ke}-28$ & 950 & 838,0535 & 111,9465 & $88 \%$ \\
\hline $\mathrm{Ke}-29$ & 950 & 956,1305 & 6,1305 & $99 \%$ \\
\hline $\mathrm{Ke}-30$ & 900 & 943,2248 & 43,2248 & $95 \%$ \\
\hline $\mathrm{Ke}-31$ & 1020 & 811,7173 & 208,2827 & $80 \%$ \\
\hline $\mathrm{Ke}-32$ & 800 & 823,3154 & 23,3154 & $97 \%$ \\
\hline $\mathrm{Ke}-33$ & 800 & 825,5868 & 25,5868 & $97 \%$ \\
\hline $\mathrm{Ke}-34$ & 800 & 825,5868 & 25,5868 & $97 \%$ \\
\hline $\mathrm{Ke}-35$ & 780 & 836,3385 & 56,3385 & $93 \%$ \\
\hline $\mathrm{Ke}-36$ & 910 & 981,8713 & 71,8713 & $93 \%$ \\
\hline $\mathrm{Ke}-37$ & 1010 & 958,7413 & 51,2587 & $95 \%$ \\
\hline $\mathrm{Ke}-38$ & 1050 & 869,0771 & 180,9229 & $83 \%$ \\
\hline $\mathrm{Ke}-39$ & 1000 & 980,2413 & 19,7587 & $98 \%$ \\
\hline $\mathrm{Ke}-40$ & 1010 & 948,2984 & 61,7016 & $94 \%$ \\
\hline $\mathrm{Ke}-41$ & 1000 & 948,2984 & 51,7016 & $95 \%$ \\
\hline $\mathrm{Ke}-42$ & 900 & 938,4805 & 38,4805 & $96 \%$ \\
\hline $\mathrm{Ke}-43$ & 1000 & 914,0274 & 85,9726 & $91 \%$ \\
\hline $\mathrm{Ke}-44$ & 900 & 835,7083 & 64,2917 & $93 \%$ \\
\hline $\mathrm{Ke}-45$ & 900 & 913,1624 & 13,1624 & $99 \%$ \\
\hline $\mathrm{Ke}-46$ & 900 & 960,6148 & 39,3852 & $96 \%$ \\
\hline $\mathrm{Ke}-47$ & 1000 & 838,7703 & 161,2297 & $84 \%$ \\
\hline $\mathrm{Ke}-48$ & 1000 & 866,4626 & 93,5374 & $90 \%$ \\
\hline $\mathrm{Ke}-49$ & 900 & 846,9283 & 53,0717 & $94 \%$ \\
\hline $\mathrm{Ke}-50$ & 800 & 835,4035 & 64,5965 & $93 \%$ \\
\hline $\begin{array}{c}\text { Rata- } \\
\text { rata }\end{array}$ & 953,7 & 929,2108 & 69,9080 & $93 \%$ \\
\hline
\end{tabular}
perangkat lunak yang dibangun bebas dari kesalahan sintaks dan secara fungsional mengeluarkan hasil yang sesuai dengan yang

Hasil perbandingan diatas dapat disimpulkan bahwa riil dengan metode Fuzzy 
dapat berjalan dengan baik dengan selisih normal, lihat di Gambar 13. Grafik Hasil Perbandingan Order.
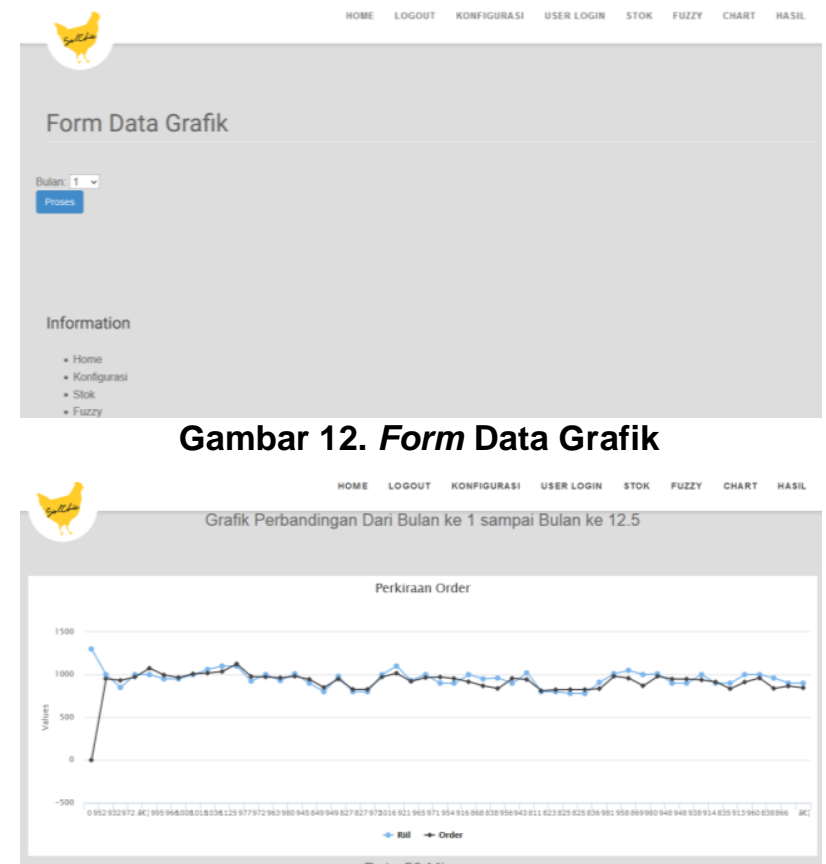

Gambar 13. Grafik Hasil Perbandingan Order

Keterangan :

$-($ Biru $)=$ Riil

$\rightarrow($ Hitam $)=$ Order

Dari form data grafik kita pilih bulan ke-12 untuk menampilkan grafik perbandingan, grafik diatas menunjukan perbandingan dari bulan ke-1 sampai bulan ke-12,5, dimana 12,5 bulan dengan data 50 minggu yang ditampilkan perbandingan dengan selisih antara data riil dan data hasil perhitungan fuzzy dengan selisih order tertinggi 347 stok ayam potong dan selisih terendah 3 stok ayam potong dan rata - rata selisih stok order adalah 70 stok ayam potong.

\section{PENUTUP}

\subsection{Kesimpulan}

Berdasarkan tujuan pembahasan untuk membuat suatu sistem Optimasi stok menggunakan metode fuzzy pada Fuzzy Tsukamoto guna memajukan rumah makan dan menjadikan lebih baik dalam pengelolaan stok menyimpulkan bahwa:

1. Optimasi sistem aplikasi stok ayam potong pada Rumah Makan Boyolali menggunakan metode Fuzzy Tsukamoto telah dirancang dengan analisa sistem menggunakan flowchart sistem, desain input output dan aplikasi PHP.

2. Pengujian sistem telah terbukti tingkat validitasnya disimpulkan bahwa perangkat lunak yang dibangun bebas dari kesalahan sintaks untuk hasil yang sesuai dengan yang diharapkan. Dan nilai optimasi dari output program telah valid dengan nilai sistem secara manual, sehingga semua fungsi pada aplikasi Fuzzy dengan metode Tsukamoto dapat berjalan dengan valid. Perbandingan data order riil dengan hasil fuzzy memiliki akurasi diatas $70 \%$ dengan rata-rata akurasi $93 \%$.

\subsection{Saran}

Penulis menyadari bahwa penelitian yang dilakukan masih memiliki banyak kekurangan. Oleh karena ini, penulis mengajukan beberapa saran yang dapat membantu proses pengembangan sistem nantinya, antara lain :

1. Pengembangan lebih lanjut terhadap aplikasi ini, dapat dilakukan beberapa penambahan berupa perhitungan beberapa variabel seperti variabel biaya, waktu dan lain lain agar mendapat hasil yang lebih optimal.

2. Menambahkan aturan fuzzy pada inferensinya, sehingga hasil yang diperoleh lebih akurat, menggunakan metode lain seperti algoritma genetika atau metode lainnya.

3. Menerapkan dalam bahasa pemrograman lain, misalnya java, $\mathrm{C}++$, visual basic, android dan lain-lain.

\section{DAFTAR PUSTAKA}

[1] R. Indonesia, Keputusan Presiden No. 969 Tahun 2014 Tentang Peraturan Menteri Pariwisata Dan Ekonomi Kreatif RI Tahun 2014, No. 12, Jakarta : Sekretariat Negara, 2014.

[2] F. Dernoncourt, Introduction to Fuzzy Logic, USA : Massachusetts Institute of Technology, 2013.

[3] M. I. Perangin-Angin, A. H. Lubis, I. S. Dumayanti, R. B. Ginting, and A. P. U. Siahaan, "Implementation of Fuzzy Tsukamoto Algorithm in Determining Work Feasibility," Journal of Computer Engineering (IOSR-JCE), vol. 19, no. 4, pp. 52-55, 2017.

[4] T. Sutojo, E. Mulyanto, and V. Suhartono, Kecerdasan Buatan, Yogyakarta: Andi Offset, 2011.

[5] K. Yusmiarti, "Perancangan Sistem Distribusi Produk Teh Hitam Berbasis Web Pada PTPN VII Gunung Dempo Pagar Alam," Jurnal Informatika AMIK 
Lembah Dempo Pagaralam, vol. 4, no. 2, pp. 1-9, 2016.

[6] A. Solichin, Pemrograman web dengan PHP dan MySQL, Jakarta : Penerbit Budi Luhur, 2016.

[7] T. MySQL, MySQL 5.7 Reference Manual, USA : Oracle Corporation, 2018.

[8] R. Sovia, J. Febio, "Membangun Aplikasi E-Library Menggunakan Html, Php Script, Dan Mysql Database," Jurnal Processor, vol. 6, no. 2, pp. 38-54, 2017.

[9] R. V. Palit, Y. D. Y. Rindengan, and A. S. M. Lumenta, "Rancangan Sistem Informasi Keuangan Gereja Berbasis Web Di Jemaat GMIM Bukit Moria Malalayang," Jurnal Teknik Elektro dan Komputer UNSRAT, vol. 4, no. 7, pp. 1-7, 2015.

[10] Sugiyono, Metode Penelitian Kuantitatif, Kualitatif, dan R\&D, Bandung : Alfabeta, 2017.

[11] R. Taufiq, H. P. Sari, "Rancang Bangun Sistem Pendukung Keputusan Penentuan Jumlah Produksi Menggunakan Metode Fuzzy Tsukamoto," Jurnal Teknik Universitas Muhammadiyah Tangerang, vol. 8, no. 1, pp. 6-10, 2019.

[12] Y. Wibowo, B. H. Purnomo, and Y. R. Maulida, "Rencana Produksi Olahan Kopi Di Perusahaan Daerah Perkebunan (Pdp) Kahyangan Jember Menggunakan Metode Fuzzy Tsukamoto," Jurnal Agrointek, vol. 13, no. 1, pp. 61-71, 2019.

[13] M. Arizal, N. Dengen, and Islamiyah, "Aplikasi Logika Fuzzy Dalam Optimisasi Stok Bahan Menggunakan Metode Tsukamoto," Prosiding Seminar IImu Komputer dan Teknologi Informasi, vol. 2, no. 1, pp. 86-90, 2017.

[14] Syahnandar, R. Hidayatullah, N. Rubiati, R. Kurniawan, "Implementasi Fuzzy Logic Penentuan Kelayakan Karyawan Mendapat Reward Ditoko Roti Mengunakan Metode Tsukamoto," Jurnal Informatika Manajemen dan Komputer, vol. 10, no. 2, pp. 56-65, 2017.

[15] L. Rohimah, "Prediksi Nilai Ekspor Sepatu Kulit Hs 6403 Ke Jepang Dengan Metode Mamdani, Sugeno, Dan Tsukamoto," Jurnal IImu Pengetahuan Dan Teknologi Komputer, vol. 4, no. 2, pp. 239-243, 2019. 